\title{
GROUND SOURCE HEAT PUMPS AND THEIR INTERACTIONS WITH UNDERGROUND RAILWAY TUNNELS IN AN URBAN ENVIRONMENT-A REVIEW
}

\author{
Akos REVESZ ${ }^{(*)}$, Issa CHAER ${ }^{(*)}$, Jolyon THOMPSON $^{(* *)}$, Maria MAVROULIDOU $^{(*)}$, Mike \\ GUNN $^{(*)}$, Graeme MAIDMENT ${ }^{(*)}$ \\ ${ }^{(*)}$ London South Bank University, 103 Borough Road, London, SE1 0AA, United Kingdom \\ Email: revesza@1sbu.ac.uk \\ ${ }^{(* *)}$ Parsons Brinckerhoff, Westbrook Mills, Godalming, Surrey, GU7 2AZ, United Kingdom
}

\begin{abstract}
Ground source heat pumps (GSHPs) can provide an efficient way of heating and cooling buildings due to their high operating efficiencies. The implementation of these systems in urban environments could have further benefits. In such locations the ground source heat is potentially more accessible through alternative sources such as through underground railways (URs). The heat from the ground surrounding an UR tunnel could be exploited to enhance the operation of GSHPs operating in heating mode. To achieve this, the interactions of GSHPs with neighbouring URs must be fully understood but there is little exploration of these in current literature. This paper focuses on the potential benefit of understanding such interactions. It starts with a summary of typical and alternative heat sources for heat pumps and then it highlights the reasons why URs can be regarded as one of the most attractive ones. Then the paper reviews the current approaches used to model GSHPs and URs. Based on that review the paper suggests a method for the combined analysis of GSHPs and URs. The reasons why London is a sensible choice for a case study are also described. Summary of results from a preliminary investigation are also presented.
\end{abstract}

Keywords: Ground Source Heat Pumps, Underground Railways, Thermal Interactions, Mathematical Modelling, Heat Recovery, London

\section{INTRODUCTION}

In March 2007, the European Council made a commitment to reduce greenhouse gas emissions by $20 \%$ by 2020 (European Commission, 2009a). The British Government went further and established a target to reduce the nation's carbon dioxide emissions overall by $80 \%$ by 2050 in comparison to a 1990 reference point (The Stationery Office, 2008). Shortly after that the Renewable Energy Directive (European Commission, 2009b) set a target for the UK that 15\% of its energy demand would be supplied from renewable sources by 2020. As part of The Renewable Energy Strategy (Secretary of State for Energy and Climate Change, 2009) the UK Government indicated that the target could be achieved with $12 \%$ of heat energy demand being satisfied by renewable sources. Financial incentives such as the Renewable Heat Incentive (DECC, 2011) designed to encourage the uptake of renewable heat technologies in the UK started to appear at that time. Heat pumps are one of the technologies to become incentivised.

\subsection{Heat Pumps - Typical And Alternative Heat Sources}

Typically heat pumps use electricity to raise the temperature of low grade heat to high grade. The Coefficient of Performance (CoP), which indicates the efficiency, depends largely on the temperature difference between the heat source and the heat supplied: The greater the difference, the less efficient the heat pump. Common sources of heat for heat pumps include ground, air and water. GSHPs have higher operating efficiencies compared to air source heat pumps. This is because the ground usually has a lower temperature than the outdoor air during the cooling season, and a higher temperature than the outdoor air in the heating season. GSHPs systems typically require between $0.22-0.35 \mathrm{kWh}$ of electricity for each $\mathrm{kWh}$ of heating or cooling output. This can be $30-50 \%$ less than the seasonal power consumption of air-to-air heat pumps (Lund et al., 2004). Therefore implementing GSHPs is an increasingly common practice. The schematics of the two common types of GSHP system configuration i.e. open and closed loop systems are illustrated in Figure 1. In urban settings heat is potentially more easily accessible through alternative sources. It was shown that the 
total heat that could be delivered from secondary sources in London is of the order of $71 \mathrm{TWh} / \mathrm{yr}$ (The Greater London Authority and Buro Happold, 2013). This was estimated by using heat pumps that delivered heat at $70^{\circ} \mathrm{C}$. This was more than the city's total heat demand of $66 \mathrm{TWh} / \mathrm{yr}$ in 2010 . Of this $71 \mathrm{TWh} / \mathrm{yr}$, around $50 \mathrm{TWh} / \mathrm{yr}(70 \%)$ would be from the secondary heat source itself and the remaining $21 \mathrm{TWh} / \mathrm{yr}$ (30\%) would be attributed to the heat pump energy requirements. Some of these secondary heat sources are summarized in Table 1. The focus of this paper is on UR as an alternative source of heat.

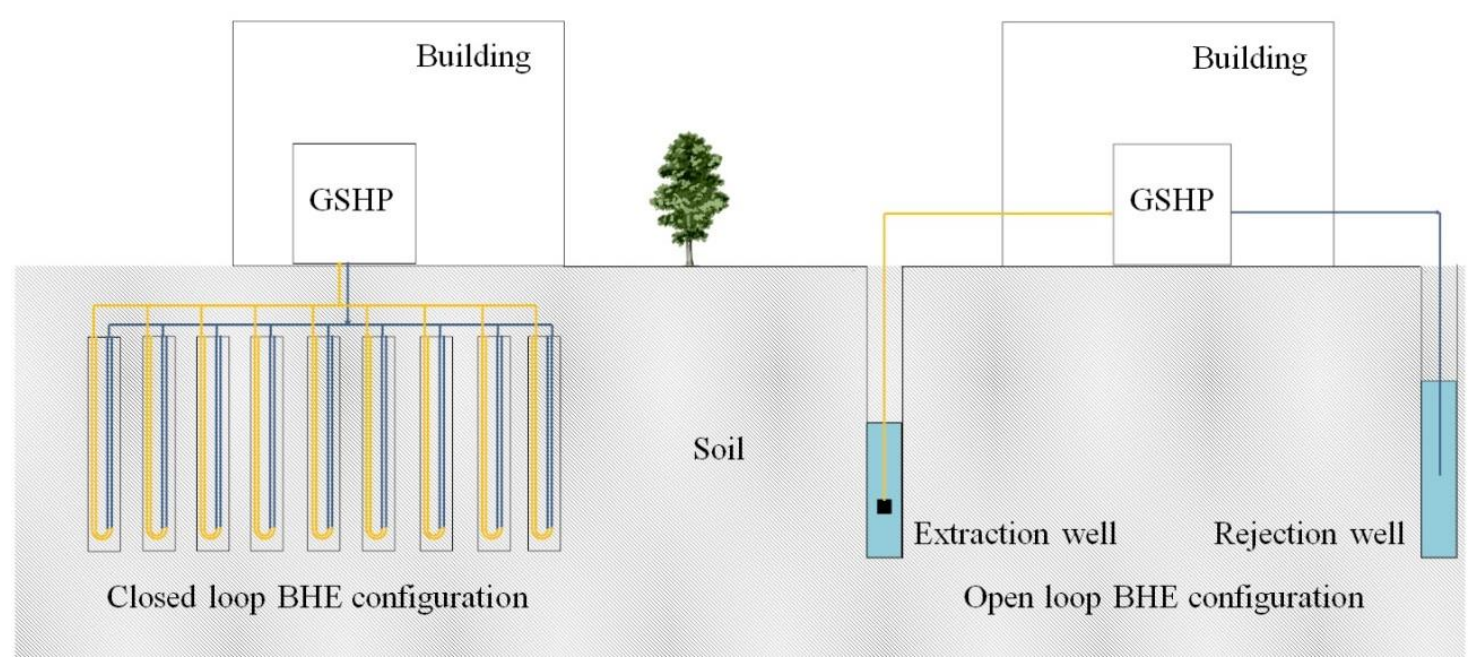

Figure 1 Schematic of the closed and open loop type GSHP configurations

Table 1 Alternative heat sources for heat pumps (Adapted from: The Greater London Authority, 2013)

\begin{tabular}{|c|l|c|}
\hline Heat Source & \multicolumn{1}{|c|}{ Description } & $\begin{array}{c}\text { Typical source } \\
\text { temperature }\end{array}$ \\
\hline $\begin{array}{c}\text { Power station } \\
\text { rejection }\end{array}$ & $\begin{array}{l}\text { Power stations that burn fuel to generate electricity generally } \\
\text { operate at electrical efficiencies of around } 30-50 \% \text { depending on } \\
\text { fuel type and technology. Considerable energy is lost in the form } \\
\text { of waste heat that is generally rejected to the atmosphere. }\end{array}$ & $\begin{array}{c}35^{\circ} \mathrm{C} \\
\text { (in some cases } \\
\text { much higher) }\end{array}$ \\
\hline $\begin{array}{c}\text { Building cooling } \\
\text { system heat } \\
\text { rejection }\end{array}$ & $\begin{array}{l}\text { Buildings use a range of different cooling systems which } \\
\text { typically operate more during summer months and use air or } \\
\text { water cooled chillers to reject heat at low temperatures. }\end{array}$ & $28^{\circ} \mathrm{C}$ \\
\hline $\begin{array}{c}\text { Industrial } \\
\text { sources }\end{array}$ & $\begin{array}{l}\text { A number of industrial processes e.g. chemical industries, } \\
\text { clinical waste incinerators and food producers lead to the } \\
\text { rejection of waste heat. }\end{array}$ & $\begin{array}{r}\text { Highly variable } \\
35-70^{\circ} \mathrm{C}\end{array}$ \\
\hline $\begin{array}{c}\text { Commercial } \\
\text { buildings non- } \\
\text { HVAC }\end{array}$ & $\begin{array}{l}\text { Some buildings reject heat from equipment other than building } \\
\text { cooling systems (e.g. from food refrigeration, IT equipment). } \\
\text { Two key commercial operations are supermarkets and data } \\
\text { centres. }\end{array}$ & $32-40^{\circ} \mathrm{C}$ \\
\hline $\begin{array}{c}\text { Underground } \\
\text { Railways } \\
\text { (Direct) }\end{array}$ & $\begin{array}{l}\text { There is a substantial amount of heat generated through the } \\
\text { operation of URs. Recovering that heat through heat exchangers } \\
\text { directly linked to the tunnel body is viable. }\end{array}$ & Can be high as \\
$35^{\circ} \mathrm{C}$
\end{tabular}




\begin{tabular}{|c|l|c|}
\hline $\begin{array}{c}\text { Underground } \\
\text { Railways } \\
\text { (Indirect) }\end{array}$ & $\begin{array}{l}\text { The ground surrounding a typical urban UR tunnel contains a } \\
\text { substantial amount of heat energy, which might be extracted } \\
\text { with nearby GSHPs. }\end{array}$ & $\begin{array}{c}\text { Typically between } \\
20 \text { and } 30^{\circ} \mathrm{C} \\
\text { depending on the } \\
\text { distance from the } \\
\text { tunnel. }\end{array}$ \\
\hline $\begin{array}{c}\text { Electricity } \\
\text { substations }\end{array}$ & $\begin{array}{l}\text { Electricity substations in both the transmission and distribution } \\
\text { networks contain transformers to convert power from one } \\
\text { voltage to another. Transformer coils are usually cooled and } \\
\text { insulated by being immersed in insulating oil. }\end{array}$ & $50^{\circ} \mathrm{C}$ \\
\hline $\begin{array}{c}\text { Sewer heat } \\
\text { mining }\end{array}$ & $\begin{array}{l}\text { Sewage in underground sewers contains heat which can be } \\
\text { tapped' or 'mined' in a similar way to the extraction of heat } \\
\text { from the ground or rivers. }\end{array}$ & $14-22^{\circ} \mathrm{C}$ \\
\hline $\begin{array}{c}\text { Roads / Car } \\
\text { parks }\end{array}$ & $\begin{array}{l}\text { The exploitation of heat stored in roads and car parks can be } \\
\text { recovered through asphalt solar collectors. }\end{array}$ & $25^{\circ} \mathrm{C}$ \\
\hline
\end{tabular}

\subsection{Underground Railways - A Continuous Heat Source}

In many capital and large cities internationally, a UR is a major public transport system and serves millions of passengers every day. In 2012 the Paris Metro carried nearly 1.5 billion passengers, the London Underground Metro system approximately 1.1 billion, and the Madrid Metro nearly 700 million passengers (ERRAC and UITP, 2012). Commuters are demanding more frequent and faster trains that are likely to result in a rising energy consumption, a large proportion of which will ultimately be rejected into the tunnel as heat. Often a large quantity of kinetic energy is generated when the trains brake. A good proportion of this energy can be regenerated, but the remainder still presents a great thermal stress on the tunnel environment. This was evidenced by Ampofo et al. (2004) who demonstrated that the major contributor of heat to the tunnel is the braking mechanism and that to the train carriage is the passengers. This is illustrated in Figure 2. Another contributing factor to rising temperatures is the climate change. Railway infrastructure has a lifespan of over 100 years and over this period climate change could potentially cause several degrees Celsius of warming. Over time, in addition to the changes that occur due to the operation of trains, the in-tunnel environment would experience change similar to the outside environment. The soil surrounding a typical deep UR tunnel also contains a large amount of heat energy due to the heat sink effect that the ground provides the tunnel. Ampofo et al. (2004) have shown that the heat absorbed by the earth surrounding an UR accounts for $30 \%$ of the total heat release, and contains approximately $4,500 \mathrm{GJ}$ of heat energy per km of tunnel. This energy is low-grade and ranges in temperature from approximately 20 to $30^{\circ} \mathrm{C}$ (Thompson et al., 2008). It is important to note that Ampofo et al. (2004) only used steady state calculations with a constant convective heat transfer coefficient. The transient balance is somewhat different and would depend on the air volume being moved within the tunnel, and so the percentage of the heat absorbed by the ground can vary significantly depending on the prevailing circumstances. Failure to manage increasing temperatures in tunnels can drive up operating costs by increasing the amount of energy required to cool the trains and stations. Energy efficiency is the first and foremost measure that can be employed to take on the challenges. This tackles the heat release at its source. Optimizing rolling stock and traction power specifications, train speed operating profiles, and maximizing regenerative braking all play a major role in reducing temperatures as well as reducing energy use. Efficient energy utilization may be further improved by heat recovery. 

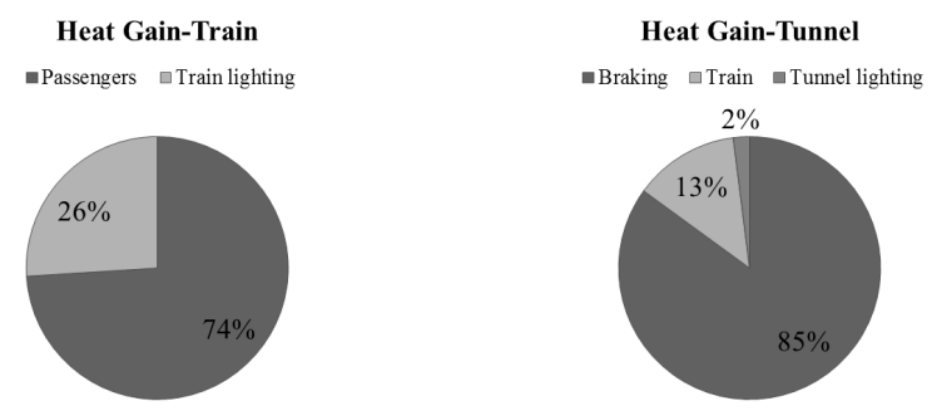

Figure 2 Heat gains in a typical underground railway environment

\subsection{Heat recovery from URs}

The heat energy provided by URs could potentially be captured, transferred and utilised by nearby users of heat. For example, a heat exchanger in the tunnel may capture the heat and a water circuit then transfer it to a heat pump. The heat pump may be connected to a third party's building or small-scale district heating system. The work of Thompson and Maidment (2010) showed that air source recovery through the ventilation system of a UR was viable (Figure 3 left). This was further supported by Gilbey et al. (2011). However neither Thompson and Maidment nor Gilbey et al. reported on the opportunity of heat recovery via an external ground loop (Figure 3 right). This is the subject of this paper. Conventional GSHPs in London typically extract heat from earth which is at about $13-14^{\circ} \mathrm{C}$ (The Greater London Authority, 2013). Utilizing source temperatures of $20-30^{\circ} \mathrm{C}$ which exist in the earth surrounding the deep bored tunnels of the LU network (Thompson et al., 2008) could substantially enhance the performance of GSHPs. An operating characteristics rule of thumb for GSHPs is that the heating CoP is improved by approximately 3\% for each degree Celsius that the evaporating temperate is raised (Cengel and Boles, 2001). Improved CoP figures would result in savings in running costs of the heat pumps, smaller heat pumps and reductions in heating related carbon emissions.

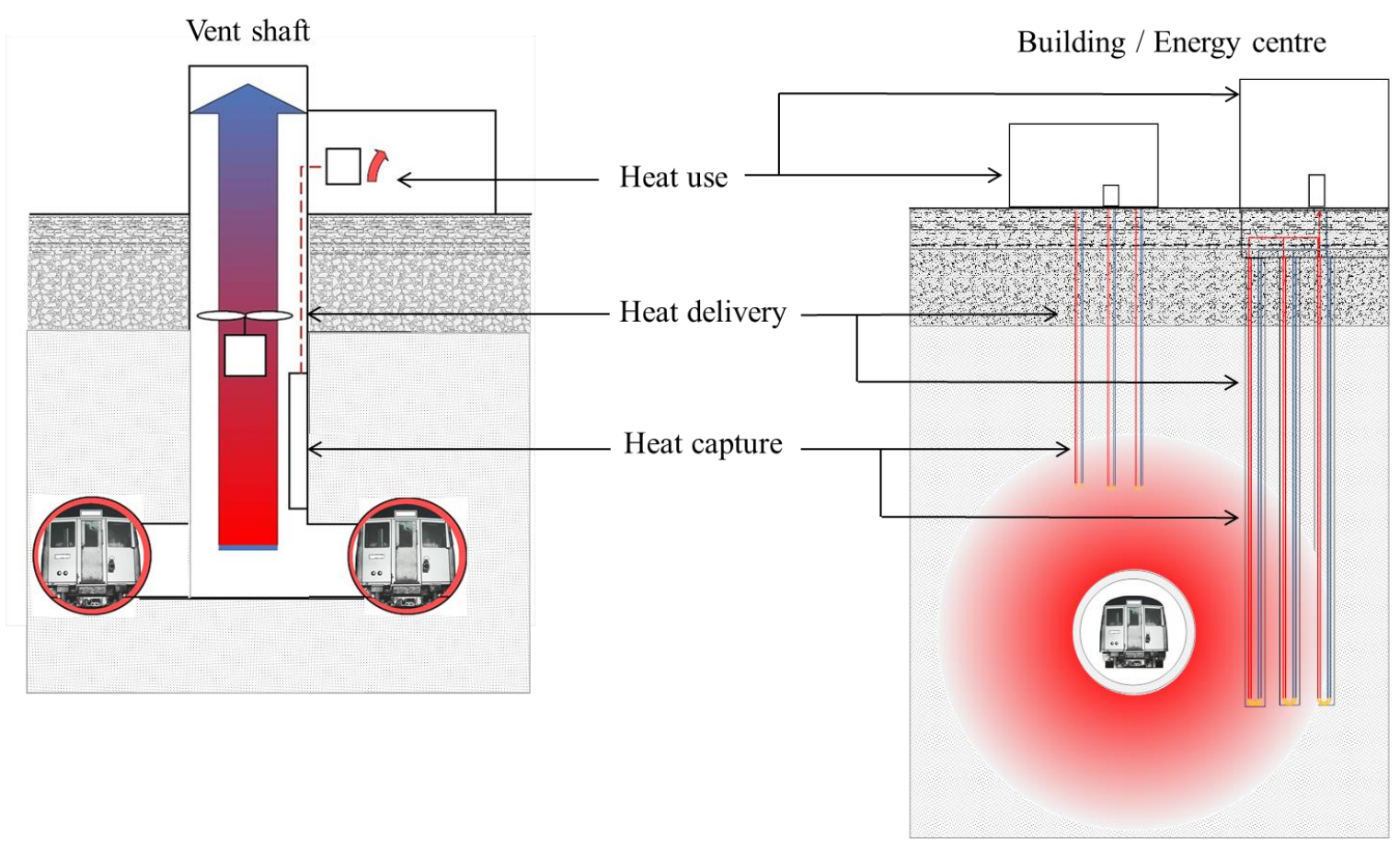

Figure 3 Heat recovery from tunnels and platforms (left) and heat recovery from the ground through BHEs (right) 


\section{MODELLING URs AND GSHPS}

A wide range of models for both GSHPs and URs have been developed, with different capabilities depending on the modelling objectives and methodology which were adopted during the development phase. Mathematical models of URs are either custom models (i.e. small models for specific sections of railway) or developed to provide a complete thermo-fluid analysis of an underground railway environment (Thompson, 2006). GSHP models can also be divided into different categories. Some models focus only on the processes within and in the surroundings of the ground heat exchangers. Other models are of integrated building simulations, whereby the entire GSHP system is coupled to HVAC and building thermal models to study overall system performance. A common feature of GSHP and UR models is that their level of detail and complexity mostly depends on the modelling objectives that are set and the timescales under consideration. The two main types of modelling approaches are numerical and analytical methodologies. Numerical methods solve the fundamental engineering equations using an established numerical differential-equation solving technique, such as a finite-difference (FD), finite-element (FE) or finite-volume (FV) method. These numerical solution methodologies are particularly useful when modelling URs and BHEs. This is because there are complex, transient, three-dimensional transport phenomena and extreme geometrical aspect ratios involved within both schemes. Numerical approaches, if designed correctly, can provide solutions for phenomena with very different time scales (e.g. the system response of coupled low and high inertia systems) and also consider a variety of transient boundary conditions. Accounting for moisture migration in the soil and ground stratification, is also typically less complicated in numerical models because they can operate with larger degrees of freedom than analytical solutions.

A common disadvantage of fully discretized 3D numerical models is that even when using modern and powerful computers, extensive computation times can result. To combat excessive runtimes, theoretical and computational assumptions and approximations have been developed. The work of Al-Khoury et al., (2005) presented a simplification for the analysis of heat flow in BHEs. The model was formulated such that it allows for the utilization of relatively large elements, alleviating thus the need for extremely fine meshes that are typically required in modelling such systems. The method of simplification to the modelling process included a specific mathematical model for the BHE. The model had an inclusion of thermal interactions among the different components of the BHE. This inclusion has lessened the need for finite element discretization of the component geometry and allowed a spatial discretization using a line element. On the other hand the use of a sequential numerical algorithm for solving the resulting system of non-linear equations has also contributed in reducing the required number of finite elements necessary for describing the involved systems. The number of elements can be decreased further using other approaches. One example is when the 3D discretization of the borehole is retained while the soil is described by a $2 \mathrm{D}$ axissymmetrical mesh. If only heat conduction considered in the horizontal cross section, the only assumption that has to be accepted is that the borehole wall has a uniform temperature in circumferential direction. Hellström, (1991) showed that the error caused by this assumption is marginal thus can be neglected.

Although analytical models that can readily be solved do have limitations, they are often used to provide data for validation purposes of numerical modelling results for both URs and BHEs. The main reason for this is that it is difficult to gather experimental data of sufficient quality and reliability in deep ground.

\subsection{Analytical UR and BHE models}

One of the earliest analytical approaches to modelling BHEs is the Line Source (LS) method where the BHE is assumed to be a line source of constant heat output surrounded by an infinite homogeneous medium. This method relies on the principle of superposition where a line consists of a combination of sequentially positioned points. First the temperature change is calculated at a specific location within an infinite homogeneous medium based on the formula of point heat source. Then integration is performed to account for the effect of the point sources positioned along the line. In the Infinite Line Source (ILS) model, which 
was developed by Ingersoll and Plass (1948), the integral of the point source formula is performed on a line with an infinite length. Another approach based on Fourier's law of heat conduction is the Infinite Cylindrical Source (ICS) method developed by Carslaw and Jaeger (1946). This method can be used to model both BHEs and UR tunnels. This method is based on a cylinder with infinite length, surrounded by a homogeneous medium with constant properties and considers heat transfers only by conduction. Also it only considers a single cross-section of a cylinder and neglects axial heat conduction effects. The first method accounting for the finite length of the BHE was developed by Eskilson (1987). The approach was based on a combination of analytical and numerical solution techniques and it is called the Finite Line Source (FLS) model. Based on Eskilson's model, Zeng et al. (2002) presented an full analytical solution to the FLS problem considering the soil as a homogeneous semi-infinite medium with constant thermo-physical properties. The ground surface was presented as a boundary with constant temperature throughout the time period considered. The heat flow rate per unit length of the borehole is assumed to be constant along the borehole. Table 2 categorises some of the work and improvements made on analytical BHE models. Enhancement of the ICS model used to model UR tunnels was initiated by several researchers including Brown et al. (2005), Brown and Vardy (2006), Sadokierski and Thiffeault (2008) and (Thompson et al., 2009).

Table 2 Improvements on analytical BHE models

\begin{tabular}{llll}
\hline \multicolumn{1}{c}{ Varying heat rate of the BHE } & \multicolumn{1}{c}{$\begin{array}{c}\text { Groundwater } \\
\text { movement }\end{array}$} & $\begin{array}{c}\text { Ground surface temp } \\
\text { changes }\end{array}$ & $\begin{array}{c}\text { Multi-layered soil } \\
\text { profile }\end{array}$ \\
\hline $\begin{array}{l}\text { Deerman and Kavanaugh, (1991) } \\
\text { [ICS }]\end{array}$ & $\begin{array}{l}\text { Diao } \text { et al., (2004) } \\
\text { [ILS] }\end{array}$ & $\begin{array}{l}\text { Bandos } \text { et al., (2009) } \\
\text { [FLS] }\end{array}$ & $\begin{array}{l}\text { Abdelaziz et al., } \\
\text { (2014) [FLS] }\end{array}$ \\
Bernier, (2001) [ICS] & $\begin{array}{l}\text { Molina-Giraldo et al., } \\
\text { (2011) [FLS] }\end{array}$ & \\
Weibo et al., (2009) [ILS] & & \\
Ozudogru et al., (2014) [FLS] & & \\
\hline
\end{tabular}

\subsection{Numerical UR and BHE models}

A number of numerical BHEs models with different features have been developed. One of the earliest is the Duct Storage model (DST), which is a two-dimensional FD scheme. The DST model was first described by Hellström (1991) and further developed by Thornton et al. (1997). The DST code was built in as a component in a simulation environment called TRNSYS. The TRNSYS is a modular system simulation package where users can describe the components that compose the system and the manner in which these components are interconnected. Other important efforts include the work of Lei (1993) and Muraya et al. (1996), who studied the thermal interference which occurs between adjacent legs of a BHE field. Most of the early numerical models were associated with low computational efficiency. In order to overcome this barrier Al-Khoury et al. (2005) developed an FE model for the analysis of three-dimensional steady state heat flow. Shortly after that a transient version of the model was presented in Al-Khoury and Bonnier (2006). More recently a three-dimensional numerical approach was developed by Rees and He (2013). The Al-Khoury and Bonnier's as well as Rees and He's approaches are suitable for the investigation of three-dimensional dynamic heat transfer and fluid flow physical phenomena. A number of design tools for BHEs based on some typical heat transfer models have been developed over the past decades.

On the other hand, numerical models aiming to study heat transfers in and around URs have also been developed. A few examples include the work of Hu et al. (2008), Ting et al. (2009), Mimouni et al. (2013) and Barla and Perino (2014). The descriptions of the implemented numerical strategies detailed within these studies however are somewhat lacking in explanation of the selected validation methodology. The most common simulation tool used in the railway industry is called the Subway Environment Simulation (SES), which was developed in the 1970s. SES is an industry standard tool in the field of tunnel ventilation. It allows engineers to mathematically model aspects of a subway environment. A supplement to the SES has been developed by Parsons Brinckerhoff to enhance the capabilities of SES. This supplement is called Dynamo, which is a one-dimensional FD model of a single length of tunnel. It uses an energy balance approach to determine the thermofluid interactions. The tool can be used for the analysis of recovery of 
waste heat from railway tunnels (Thompson, 2014). There are several tools available for designing GSHP/BHE systems such as EED, GLHEPRO, GLD, and CLGS. Typically the user must input the building loads, design area, heat exchanger configuration, pipe size and type, and heat pump capacities. In response the software usually calculates the required length of the BHEs and system CoPs, sometimes even energy consumptions and running costs of the heat pump. To date there are no models reported that allow the combined analysis of URs and nearby heat sources/heat sinks e.g. GSHPs.

\subsection{Simulation platforms for the combined analysis of URs and GSHPs}

At present a number of simulation tools are available commercially and through open source. Those that are capable of simulating heat and mass transports in the ground include FEFLOW, ANSYS and COMSOL Multiphysics, amongst others. Most of these simulation tools offer a user-programmable interface, allow the input of user-defined equations and enable linkage with other software such as CAD tools or Matlab. These tools allow the building of geometries within either a one, two or three-dimensional modelling domain, thus allowing the complex geometrical aspects of URs and GSHPs to be easily represented. These platforms usually also allow the use of a wide variety of boundary and initial conditions that would typically exist during the operation of URs and GSHPs. Thus the above-mentioned simulation platforms would allow the detailed investigation of the interactions of URs and BHEs within the same simulation environment. For building a model using such a tool it is essential to become familiar first with the parameters, variables, properties and operating conditions involved. This paper considers London and its Metro system the London Underground (LU) as a case study.

\section{LONDON - THE LINKAGE BETWEEN URS AND GSHPS}

London, the capital city of the United Kingdom, has grown to become one of the most significant financial and cultural capitals of the world. Due to this position, more people than ever are using the LU. Simultaneously, GSHP installations are becoming increasingly common in the city and thus BHEs eventually could get closer in proximity to the running tunnels. Investigating the viability of the heat recovery from the ground surrounding the tunnels through these ground loops will therefore become increasingly important. Following a brief introduction to London's geology, this section reviews the infrastructure of the LU railway and its thermal environment. The potential benefits of the interactions between the tunnels and nearby ground heat exchangers are also summarised.

\subsection{London Basin}

The centre of the city of London is part of the London Basin. Of all the lithology of the Basin, the London clay formation hosts many types of subterranean structures including the majority of the LU railway. A typical geology and a section of the LU railway network are illustrated in Figure 4. The London clay's generally low permeability and good load-bearing characteristics are some of the principal reasons for the comparatively early development of the LU (Paul, 2009). The major aquifer of the London Basin is the chalk aquifer (Environmental Agency, 2014). In the early nineteenth century, heavy water abstractions led to a fall in groundwater levels, increasing the strength of the London Clay. Legislation from the 1960s led to the slow recharge of groundwater levels. Since then, increased pumping has been required in some areas of the LU network as old tunnels are threatened by the changes in the pore water pressure in the London Clay, which will lead to increased leakage of water into the tunnel. It is also possible that such pressures would cause the tunnel linings to change shape. The shallower tunnels, often called "sub-surface" lines, are typically at a depth consistent with location in the River Terrace Gravel strata. These are known to be a porous strata often containing ground water flowing to the nearby River Thames basin. Some sections of the tunnels are run through the less well-consolidated sands of the Bagshot formation or the Lambeth Group. These formations mainly comprise highly permeable sands. 


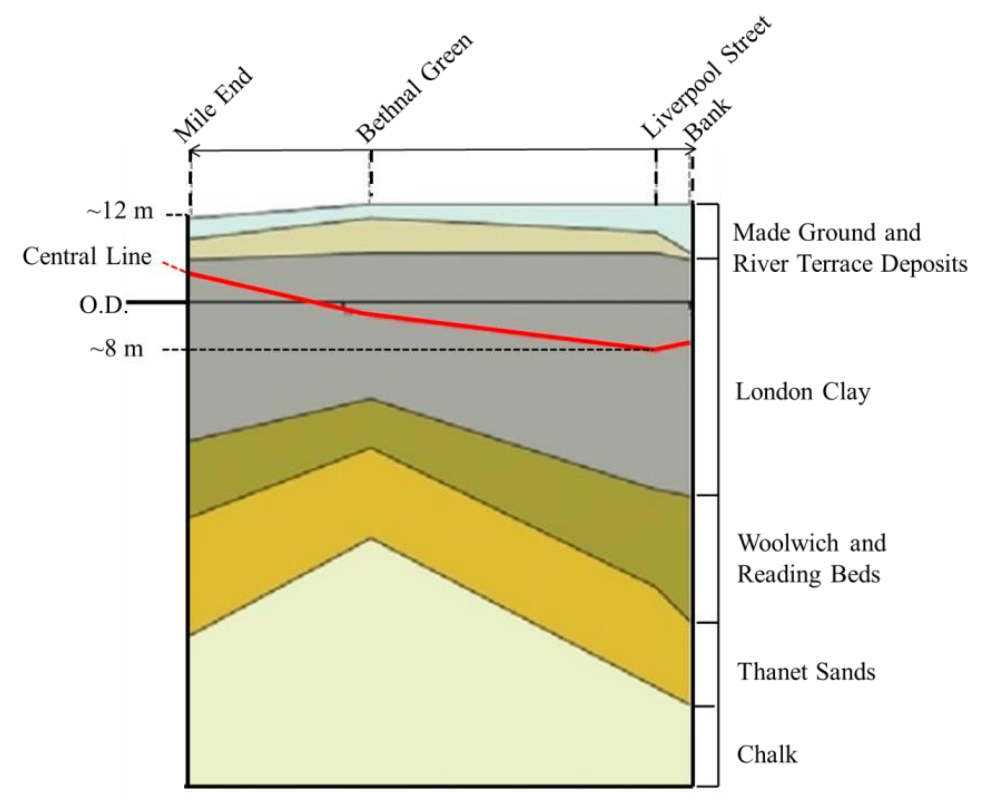

Figure 4 A short geological section following the path of the Central line of the LU railway

\subsection{The LU railway tunnels and nearby GSHPs}

The Metropolitan Railway was the first section of the LU railway. It was constructed from Paddington to Farringdon in 1860-1862 using the cut and cover technique. The railway was a great success from the beginning, attracting 11.8 million passengers in the first year. The railway was soon extended to South Kensington in the west and Tower Hill in the east. The "full circle" (today known as the Circle Line) was completed in 1884. The first two "deep tube" lines on the LU were the "City and South London Railway" and the "Central London Railway". Since then the LU network has broadly extended and currently contains approximately $35 \mathrm{~km}$ of the "sub surface lines" and about $136 \mathrm{~km}$ of the deeper tube tunnels. The average depth of the bored deep tube tunnels is $24 \mathrm{~m}$ with a maximum of $67 \mathrm{~m}$ (Thompson et al., 2008). The extension of the Northern line was recently announced that will add an extra $5 \mathrm{~km}$ to the tunnel network (Constructionenquirer, 2014). Simultaneously, GSHP installations are becoming increasingly common in the city and thus BHEs could eventually get closer in proximity to the running tunnels. A great example of a GSHP installation in close proximity to LU tunnels is the building called One New Change. The building consists in $52,000 \mathrm{~m}^{2}$ of offices and retail space on eight floors. The geothermal scheme includes 219 energy piles of up to $38 \mathrm{~m}$ deep and $2.5 \mathrm{~m}$ in diameter. To complete the hybrid GSHP system there are a pair of deep water wells to $140 \mathrm{~m}$ into the chalk. The GSHP system's total heating and cooling capacity is respectively 1.6 MW and 1.7 MW. The nearby LU Central Line tunnels run parallel to the northern boundary of the site. The tunnels run approximately 20-25 m below ground level. The piles are located at least $7 \mathrm{~m}$ clear distance from the south of the tunnel closer to the site boundary.

\subsection{The thermal environment of the $L U$ railway}

Since 2005 LU has used temperature sensors and data loggers to record the air temperatures at numerous platforms and stations. The recorded data showed that during summer peak-hour operation temperatures can reach as high as 26 and $32^{\circ} \mathrm{C}$. On the other hand on a cold winter day the platforms could still be relatively warm as $20^{\circ} \mathrm{C}$ (Thompson et al., 2008). The work of Gilbey et al. (2011) showed that there is a linear relationship between platform and outside air temperatures and it can be expressed as $\mathrm{T}_{\text {platform }}=0.36 \mathrm{x} \mathrm{T}_{\text {outside }}$ +19.5 . The authors work also showed that tunnel temperatures are typically $2-3^{\circ} \mathrm{C}$ cooler than platform air temperatures. This was explained as being a result of the heat produced by the braking mechanism concentrating at the platforms. 


\subsection{Exploitation of the low grade energy from the earth surrounding the tunnels}

The soil surrounding a typical deep level UR tunnel also contains a large amount of heat energy due to the heat sink effect that the ground provides the tunnel. This low grade energy could potentially be extracted by nearby BHEs. As these ground loops will eventually get closer in proximity to the tunnels the potential for heat recovery will become greater. However, there is a limit to how close structures can be constructed to the tunnels. The minimum proximity that LU allows is about $3 \mathrm{~m}$ in horizontal and $6 \mathrm{~m}$ in vertical directions (Transport for London, 2013) Researchers have reported different values within the literature, in terms of the distance of the thermal effects from the wall of an UR railway to the soil. Cockram and Birnie, (1976) measured the changes in soil temperature adjacent to running tunnels prior to opening the passenger traffic of the Victoria Line in London. Four years after the commencement of traffic, stable temperature conditions have not yet been reached and $9.1 \mathrm{~m}$ from the tunnel the clay temperature continued to rise. The work of HU et al.,(2008) suggests that thermal effect from the wall of an UR tunnel built in silty clay could be up to 20 $\mathrm{m}$. This means that the $136 \mathrm{~km}$ long deep bored tunnel sections with a diameter of $3.7 \mathrm{~m}$, could potentially provide significant volume of earth, perhaps over 200 million $\mathrm{m}^{3}$, containing a significant amount of low grade energy for potential exploitation by nearby BHEs connected to a heat pump. The heat pump may be connected to a third party's building or small-scale district heating system. Figure 5 illustrates the schematics of such heat capture, transfer and use.

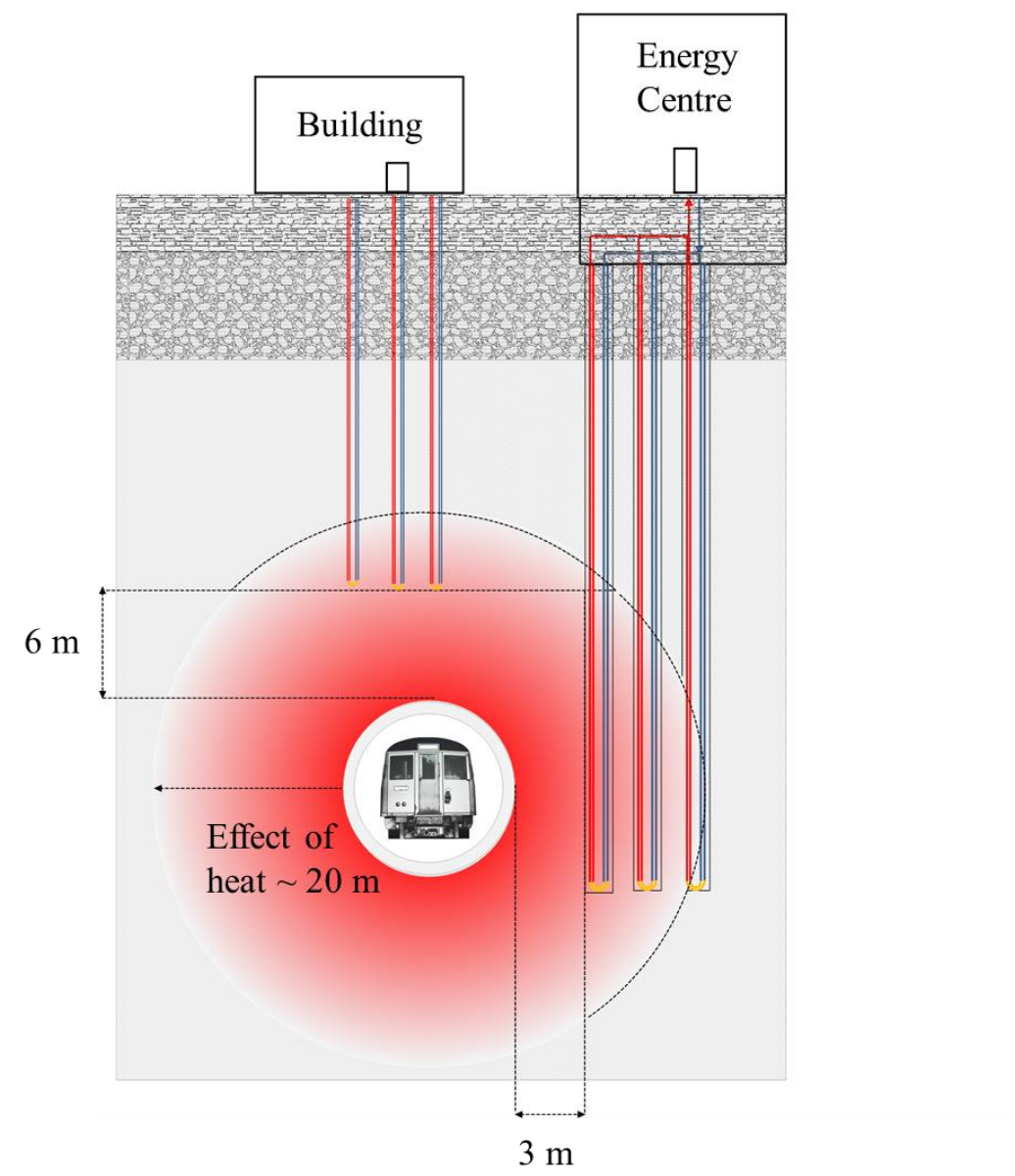

Figure 5 Heat removal from the ground surrounding the tunnels

\section{INDENTIFIED GAPS}

A number of models related to URs and GSHPs have been previously reported. Also several tools exist that allow engineers to mathematically model aspects of the subway environment or the operation of a GSHP system. However the literature lacks a combined analysis of the two schemes. Implementing previously developed modelling approaches for GSHPs and URs within the same simulation environment would make 
it possible to study the interactions of the two systems. Once a better understanding of such interactions is achieved, a detailed investigation and characterization of the most viable energy capturing and supplying solutions will be required. Additionally, identification of the key parameters that influence the interactions and the development of rules-of-thumb and designer aids are also needed to provide guidance to engineers working in fields where these interactions occur.

\section{INITIAL INVESTIGATION}

Given the limited exploration of the interactions of GSHPs and URs in current literature, a numerical investigation was conducted by the authors. The objective of the preliminary investigations was to establish key phenomena for more comprehensive research. The time dependent FE model was built with the software package COMSOL Multiphysics (COMSOL Muliphysics, 2015). The model was built in two dimensions with a simulation period of 6 years. London was chosen as a case study, thus the geometrical parameters, material properties, initial, boundary and working conditions implemented within the model were based on typical conditions for the UK capital city. Summary of the preliminary model conditions is shown in Table 3. Further details of the model development, validations and simulation results are explained in Revesz et al., (2015).

Table 3 Initial, boundary and operating conditions of the preliminary model

\begin{tabular}{|c|l|}
\hline \multirow{2}{*}{ Soil } & $\begin{array}{l}\text { The initial ground temperature within the soil domain was set based on } \\
\text { the average UK geothermal gradient. }\end{array}$ \\
\cline { 2 - 3 } & $\begin{array}{l}\text { A time dependent temperature boundary was applied on the surface of } \\
\text { the soil domain based on London's monthly average air temperatures. }\end{array}$ \\
\cline { 2 - 3 } & The lateral boundary of the soil domain was assumed to be adiabatic. \\
\hline \multirow{2}{*}{ BHE } & $\begin{array}{l}\text { The fluid flow within the pipes of the BHE was ignored and instead a } \\
\text { time periodic heat flux boundary was applied on the entire wall surface of } \\
\text { the BHE. The maximum heat load per unit BHE length is taken to be } 20 \\
\text { W/m. This value matched the operational performance the central } \\
\text { London GSHP installation site at London South Bank University. }\end{array}$ \\
\hline \multirow{2}{*}{ Tunnel } & $\begin{array}{l}\text { A time dependent temperature boundary was applied to the wall of the } \\
\text { tunnel. This was based upon the work of Gilbey et al., (2011). }\end{array}$ \\
\hline
\end{tabular}

The initial model was used to investigate the temperature variation at a point on the wall of the BHE in response to changes in the proximity of the tunnel. The horizontal distance between the tunnel and the BHE wall was varied between 50 and $3 \mathrm{~m}$. The results of the BHE wall temperatures are plotted in Figure 6 . The figure shows as the tunnel gets closer to the BHE the temperature changes at the wall of the BHE are more significant. A maximum temperature, $34^{\circ} \mathrm{C}$ at the $\mathrm{BHE}$ wall, was achieved when the proximity between the tunnel and the BHE was reduced to $3 \mathrm{~m}$. Increased BHE wall temperatures improve the heat pump CoP for heating applications. In contrast, high BHE wall temperatures are likely to reduce the efficacy of the GHSP operating in cooling mode. The main outcome of this preliminary investigation was that interaction between GSHPs and URs is a genuine phenomenon. It is therefore worth further research to promote energy efficiency in GSHP installations. It is reasonable to conclude that there are other significant parameters which impact the interactions and identifying these will be the initial objective of our further research. 


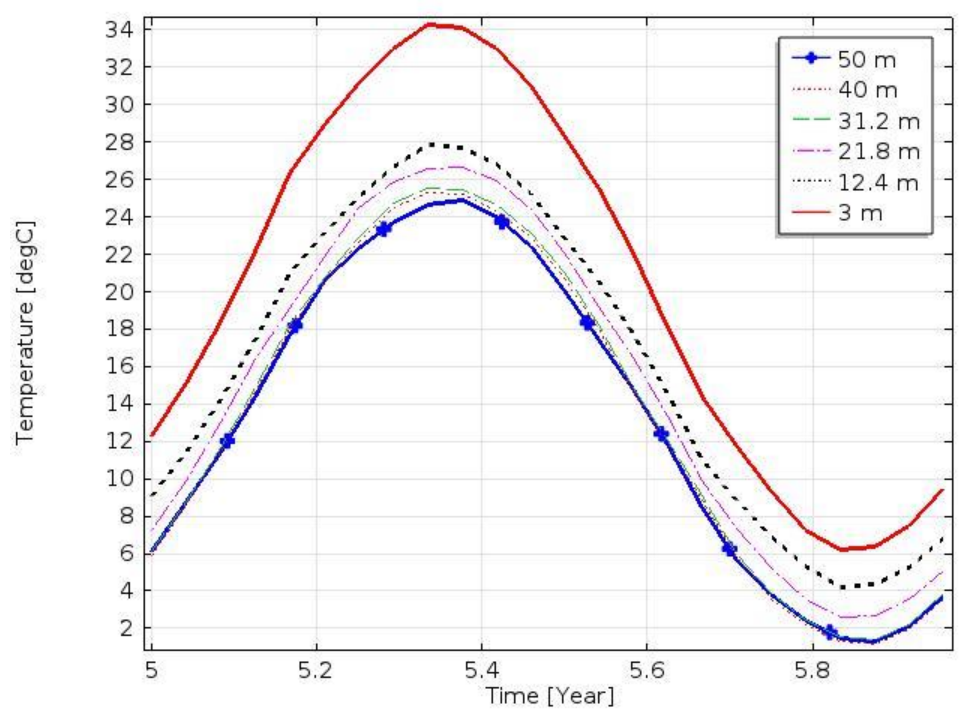

Figure 6 BHE wall temperatures versus tunnel proximity

\section{CONCLUSIONS}

Due to their high operating efficiencies, concerns about carbon emissions, and the highly incentivised nature of GSHPs, the technology has become an increasingly common choice for heating and cooling many types of buildings. In addition to the conventional heat sources, there are alternative options, such as the low- grade heat generated by URs. The soil that surrounds the railway tunnels also contains significant quantities of heat energy. This low grade energy could give an opportunity for a year-round heat supply for nearby users of heat. There is a comprehensive literature available regarding how to extract heat directly from URs, for example by placing heat exchangers within existing ventilation shafts. The literature however lacks exploration of the potential for recovering heat through the ground surrounding the tunnels via nearby ground heat exchangers. In order to explore this potential in detail, the interactions of GSHPs with neighbouring UR tunnels must first be fully understood. Investigation of such interactions requires mathematical modelling. A number of modelling approaches have been developed separately for schemes with a different level of complexity. These approaches could potentially be used for the combined analysis of the two systems. Since both URs and BHEs modelling involves complex geometrical aspect ratios and transient phenomena, the use of numerical solution methodologies are preferable. A number of numerical simulation platforms exist that would be suitable for such combined analysis. Investigating the interactions using London as a case study is a practical choice since the tunnels of the LU railway are running beneath a significant part of the central area of the city. Simultaneously, GSHP installations are becoming increasingly common in the city, thus ground heat exchangers will eventually get closer in proximity to the tunnels. Understanding the interactions between URs and nearby GSHPs would help to identify how the energy generated and eventually dissipated to the ground by urban railway systems could contribute to sustainable city planning. Key outcomes from a preliminary investigations demonstrated that interaction occurs between GSHPs and URs and therefore this field is worth further research to promote energy efficiency in GSHP installations.

\section{ACKNOWLEDGEMENTS}

The authors would like to express their gratitude for the support by London Underground Ltd and the interdisciplinary centre for Storage, Transformation and Upgrading of Thermal Energy (i-STUTE). 


\section{REFERENCES}

Abdelaziz, S. L., Ozudogru, T. Y., Olgun, C. G. and Martin II, J. R. (2014) Multilayer finite line source model for vertical heat exchangers, Geothermics, 51, pp. 406-416.

DOI:10.1016/j.geothermics.2014.03.004.

Al-Khoury, R. and Bonnier, P. G. (2006) Efficient finite element formulation for geothermal heating systems. Part II: transient, International Journal for Numerical Methods in Engineering, 67 (5), pp. 725-745. Available from: [Accessed 23 October 2014].

Al-Khoury, R., Bonnier, P. G. and Brinkgreve, R. B. J. (2005) Efficient finite element formulation for geothermal heating systems. Part I: steady state, International Journal for Numerical Methods in Engineering, 63 (7), pp. 988-1013. DOI:10.1002/nme.1313.

Ampofo, F., Maidment, G. and Missenden, J. (2004) Underground railway environment in the UK Part 2: Investigation of heat load, Applied Thermal Engineering, 24 (5-6), pp. 633-645.

DOI:10.1016/j.applthermaleng.2003.10.018.

Bandos, T. V., Montero, Á., Fernández, E., Santander, J. L. G., Isidro, J. M., Pérez, J., et al. (2009) Finite line-source model for borehole heat exchangers: effect of vertical temperature variations, Geothermics, 38 (2), pp. 263-270. DOI:10.1016/j.geothermics.2009.01.003.

Barla, M. and Perino, A. (2014) Energy from geo-structures: a topic of growing interest, Environmental Geotechnics. DOI:10.1680/envgeo.13.00106.

Bernier, M. A. (2001) SYMPOSIUM PAPERS-AT-01-8 Pumping Design and Performance Modeling of Geothermal Heat Pump Systems-Ground-Coupled Heat Pump System Simulation, ASHRAE Transactions-American Society of Heating Refrigerating Airconditioning Engin, 107 (1), pp. 605-616.

Brown, J. M. B. and Vardy, A. E. (2006) Practical evaluation of convective heat exchanges between deep tunnels and the surrounding ground, Slovenia.

Brown, J. M. B., Vardy, A. E. and Tijsseling, A. S. (2005) Response of wall heat transfer to flows along a cylindrical cavity and to seepage flows in the surrounding medium, Journal of Water Resources, 26 (2), pp. 57-68.

Carslaw, H. . and Jaeger, J. C. (1946) Conduction of Heat in Solids. Oxford, UK: Claremore Press.

Cengel, Y. A. and Boles, M. A. (2001) Thermodynamics: An Engineering Approach. 4th edition. Boston: Mcgraw-Hill College.

Cockram, I. J. and Birnie, G. R. (1976) The ventilation of London's underground railways, in: Proceedings of the Second International Symposium on the Aerodynamics and Ventilation of Vehicle Tunnels, Paper H.2, pp. 11-27.

COMSOL Muliphysics (Version 5.0) (2015). Available from: http://www.uk.comsol.com/

Constructionenquirer (2014) Northern line extension green light for spring start I Construction Enquirer. Available from: http://www.constructionenquirer.com/2014/11/13/northern-lineextension-go-ahead-for-spring-start/[Accessed 18 November 2014]. 
DECC (2011) Renewable Heat Incentive. Available from:

https://www.gov.uk/government/uploads/system/uploads/attachment_data/file/48041/1387renewable-heat-incentive.pdf [Accessed 6 October 2014].

Deerman, J. D. and Kavanaugh, S. P. (1991) Simulation of Vertical U-Tube Ground-Coupled Heat Pump Systems Using The Cylindrical Heat Source Solution. Available from:

http://www.techstreet.com/products/1717186\#jumps [Accessed 22 October 2014].

Diao, N., Li, Q. and Fang, Z. (2004) Heat transfer in ground heat exchangers with groundwater advection, International Journal of Thermal Sciences, 43 (12), pp. 1203-1211.

DOI:10.1016/j.ijthermalsci.2004.04.009.

Environmental Agency (2014) Management of the London Basin Chalk Aquifer. Available from: https://www.gov.uk/government/uploads/system/uploads/attachment_data/file/320038/2014_Londo n_GWL_Report.pdf [Accessed 17 March 2015].

ERRAC and UITP (2012) Metro, light rail and tram systems in Europe, UITP - Advancing Public Transport. Available from: http://www.uitp.org/metro-light-rail-and-tram-systems-europe [Accessed 10 October 2014].

Eskilson, P. (1987) Thermal Analysis of heat extraction boreholes. Available from: http://www.buildingphysics.com/Eskilson1987.pdf [Accessed 17 March 2015].

European Commission (2009a) Decision No 406/2009/EC on the effort of Member States to reduce their greenhouse gas emissions to meet the Community's greenhouse gas emission reduction commitments up to 2020. Official Journal of the European Union. Available from: http://eurlex.europa.eu/LexUriServ/LexUriServ.do?uri=OJ:L:2009:140:0136:0148:EN:PDF [Accessed 2 October 2014].

European Commission (2009b) Directive 2009/28/EC of the European Parliament and of the Council on the promotion of the use of energy from renewable sources and amending and subsequently repealing Directives 2001/77/EC and 2003/30/EC. Available from: http://www.ecolex.org/ecolex/ledge/view/RecordDetails;jsessionid=81486EE7CA5E560409D3923 98C9539A0?id=LEX-FAOC088009\&index=documents [Accessed 5 October 2014].

Gilbey, M., Thompson, J. and Duffy, S. (2011) The Potential for Heat Recovery from London Underground Stations and Tunnels, in: CIBSE Technical Symposium. Leicester UK.

Hellström, G. (1991) Ground heat storage : thermal analyses of duct storage systems (dissertation). Lund University, Lund, Sweden. Available from : http://lup.lub.lu.se/record/2536279 [Accessed 5 November 2014].

HU, Z., LI, X., ZHAO, X., XIAO, L. and WU, W. (2008) Numerical analysis of factors affecting the range of heat transfer in earth surrounding three subways, Journal of China University of Mining and Technology, 18 (1), pp. 67-71. DOI:10.1016/S1006-1266(08)60015-2.

Ingersoll, L. and Plass, H. (1948) Theory of the ground heat pipe heat source for the heat pump, Transactions of the American Society of Heating and Ventilating Engineers. Available from: http://www.citeulike.org/user/fghorow/article/4097264 [Accessed 17 March 2015].

Lei, T. (1993) Development of a computational model for a ground-coupled heat exchanger, ASHRAE Transaction, 99. 
Lund, J., Sanner, B., Rybach, L., Curtis, R. and Hellstrom, G. (2004) Geothermal (Ground-Source) Heat Pums A World Overview. Geo - Heat Center. Available from:

http://file.seekpart.com/keywordpdf/2011/5/24/2011524112558636.pdf [Accessed 10 October 2014].

Mimouni, T., Dupray, F., Minon, S. and Laloui, L. (2013) Heat Exchanger Anchors for Thermoactive Tunnels. Available from: http://infoscience.epfl.ch/record/190673 [Accessed 28 October 2014].

Molina-Giraldo, N., Blum, P., Zhu, K., Bayer, P. and Fang, Z. (2011) A moving finite line source model to simulate borehole heat exchangers with groundwater advection, International Journal of Thermal Sciences, 50 (12), pp. 2506-2513. DOI:10.1016/j.ijthermalsci.2011.06.012.

Muraya, N., O’Neal, D. and Heffington, W. (1996) Thermal interference of adjacent legs in a vertical u-tube heat exchanger for a ground-coupled heat pump, ASHRAE Transaction, 102 (Paper number 3980), pp. 12-21.

Ozudogru, T. Y., Olgun, C. G. and Senol, A. (2014) 3D numerical modeling of vertical geothermal heat exchangers, Geothermics, 51, pp. 312-324. Available from: [Accessed 22 October 2014].

Paul, J. D. (2009) Geology and the London Underground, Geology Today, 25 (1), pp. 12-17. DOI:10.1111/j.1365-2451.2009.00699.x.

Rees, S. J. and He, M. (2013) A three-dimensional numerical model of borehole heat exchanger heat transfer and fluid flow, Geothermics, 46, pp. 1-13. DOI:10.1016/j.geothermics.2012.10.004.

Revesz, A., Chaer, I., Thompson, J., Mavroulidou, M., Gunn, M. and Maidment, G. (2015) Interactions of ground source heat pumps with nearby underground railway tunnels in an urban environment, The $24^{\text {th }}$ IIR International Congress of Refrigeration, Yokohama, Japan.

Sadokierski, S. and Thiffeault, J.-L. (2008) Heat Transfer in Underground Rail tunnels. Available from: http://arxiv.org/pdf/0709.1748.pdf [Accessed 17 March 2015].

Secretary of State for Energy and Climate Change (2009) The UK Renewable Energy Strategy. HM Government. Available from:

https://www.gov.uk/government/uploads/system/uploads/attachment_data/file/228866/7686.pdf [Accessed 17 March 2015].

The Greater London Authority and Buro Happold (2013) LONDON'S ZERO CARBON ENERGY RESOURCE. Available from:

http://www.london.gov.uk/sites/default/files/031250\%20GLA\%20Secondary\%20Heat\%20-

\%20Summary\%20Report.pdf [Accessed 10 January 2015$].$

The Stationery Office (2008) Climate Change Act 2008. Available from:

http://www.legislation.gov.uk/ukpga/2008/27/pdfs/ukpga_20080027_en.pdf [Accessed 2 October 2014].

Thompson, J. (2014) Dynamo - Enhancing Tunnel Ventilation Modelling, Parsons Brinckerhoff Network, 78, pp. 63-66.

Thompson, J. A. (2006) Sustainable Cooling Of Undergound Railways Through Enhancement Of The Heat Sink Effect. London, UK. 
Thompson, J. A., Missenden, J. F., Gilbey, M. and Maidment, G. G. (2009) Response of wall heat transfer to steady and transient flows along a cylindrical cavity, in: New Brunswick, New Jersey, USA.

Thompson, J., Gilbey, M. and Maidment, G. (2008) Geothermal cooling of underground railwaysthe opportunity, in: UK, London: The Institute of Refrigeration, Volume 105.

Thompson, J. and Maidment, G. (2010) Alternative geothermal heating sources, heat pumps and their application, in: 1st IIR International Conference on the Cold Chain and Sustainability.

Cambridge, UK.

Thornton, J. W., McDowell, T. P., Shonder, J. A., Hughes, P. J., Pahud, D. and Hellstrom, G. A. (1997) Residential vertical geothermal heat pump system models: calibration to data,

TRANSACTIONS-AMERICAN SOCIETY OF HEATING REFRIGERATING AND AIR

CONDITIONING ENGINEERS, 103, pp. 660-674. Available from: [Accessed 23 October 2014].

Ting, Y. S., Gilbey, M. J., Drake, S. N., Missenden, J. F. and BHR Group Limited (2009) CFD estimation of heat transfer enhancement on a cooling pipe in underground railway tunnels, in: pp. $629-644$.

Transport for London, London Underground, (2013) Civil Engineering - Common Requirements, Category 1 Standard.

Weibo, Y., Mingheng, S. and Zhengian, C. (2009) A Variable Heat Flux Line Source Model For Boreholes In Ground Coupled Heat Pump, in: Power and Energy Engineering Conference, 2009. APPEEC 2009. Asia-Pacific. pp. 1-4.

Zeng, H. Y., Diao, N. R. and Fang, Z. H. (2002) A finite line-source model for boreholes in geothermal heat exchangers, Heat Transfer-Asian Research, 31 (7), pp. 558-567. Available from: [Accessed 21 October 2014]. 